\title{
The Use and Abuse of Machine Translation in Vocabulary Acquisition
} among L2 Arabic-Speaking Learners

\author{
Lamis Ismail Omar \\ English Language and Literature Department, College of Arts and Applied Sciences, \\ Dhofar University, Salalah, Sultanate of Oman \\ Email: lameesiomar@gmail.com
}

Received: 12/30/2020

Accepted: $1 / 17 / 2021$

Published: $2 / 24 / 2021$

\begin{abstract}
Using Machine Translation (MT) for vocabulary acquisition is an inevitable phenomenon among Arabic-speaking L2 learners. But has MT fully succeeded in replacing traditional dictionaries and providing an ideal tool for vocabulary acquisition among L2 learners? This study aimed to research the value and implications of using machine translation in vocabulary acquisition. The study is significant as it investigates a neglected area in teaching a second language focusing on the role of MT in vocabulary acquisition. The empirical study adopted a combined quantitative and qualitative methodology that tested students' skills in answering vocabulary questions in context by using online translators. Forty-seven participants took part in the assessment voluntarily, and they were all fourth-year students about to graduate from an Omani private university. The findings confirmed the results of earlier research about the challenges ESL learners face in vocabulary acquisition, including difficulties in processing sequential lexical patterns and using vocabulary communicatively. The results further revealed that online translators do not provide an optimal solution to overcome obstacles in using vocabulary unless accompanied by higher metacognitive skills such as critical thinking and using words in context. The study concluded with some implications and recommendations for further relevant research.

Keywords: English as a Second Language, Machine Translation, Omani private university, online dictionaries, online translators, pedagogy, Second Language Arabic-speaking learners, technology, vocabulary acquisition

Cite as: Omar, L. I. (2021). The Use and Abuse of Machine Translation in Vocabulary Acquisition among L2 Arabic-Speaking Learners. Arab World English Journal for Translation \& Literary Studies 5 (1) 82-98 .

DOI: http://dx.doi.org/10.24093/awejtls/vol5no1.6
\end{abstract}




\section{Introduction}

There is a universal consensus among foreign language learners, academics, and researchers that vocabulary acquisition is an integral part of second/foreign language teaching (Constantinescu, 2007; Boers \& Lindstromberg, 2008). Words are the point of departure in learning a foreign language and using it effectively. Even when used individually, a word can start a communication process and keep it going. Accordingly, it is recognized in L2 learning and teaching activities that mastering the use of lexis is both an obstacle to and a predictor of the learners' effective use of language (AlQahtani, 2015). In pedagogical practice, teaching new vocabulary in the L2 classroom takes place in parallel with reading comprehension activities as the reading skill depends on the learner's vocabulary and background knowledge in the second/foreign language (Constantinescu, 2007). Throughout the reading activity, the learners can acquire new words and practice using them in context (Nomass, 2013). Blake (2008) observed that the learners' superficial knowledge of vocabulary is detrimental to their ability to achieve full reading comprehension. AlQahtani (2015) pointed out that L2 readers face formidable challenges unless they have rich knowledge about vocabulary and their use in context. Empirically, learning vocabulary plays a vital role in the reading skill and all other language skills because it is sentential to the successful uses of language (Chandra \& Yuyun, 2018). Research has revealed that L2 learners achieve more when they have rich knowledge about vocabulary in quantity and quality (AlQahtani, 2015). Therefore, students always need to develop their vocabulary and ameliorate their ability to master their use in the four language skills equally: reading, writing, listening, and speaking (Alagozlu \& Kiymazarslan, 2020).

Teaching new vocabulary in the foreign language classroom is not an easy process for reasons to do with the lack of awareness among learners and instructors about the significance of this task and the appropriate methods to approach it. AlQahtani (2015) observed that most instructors are not well-informed about how best to teach vocabulary in the L 2 classroom and what pedagogical practices they can follow to address the challenges students encounter when learning about vocabulary uses in context. This has become more evident following the emergence of technology and its uninformed, ubiquitous uses in L2 learning activities. Al-Qahtani (2015) discussed the techniques used by L2 instructors in teaching vocabulary, including the use of objects, drawings, illustrations, pictures, contrasting vocabulary with their antonyms, enumeration, mime, gestures, guessing from context, eliciting as well as translation. 'Translation' came at the end of the list, implying that it should be the last resort of EFL instructors in teaching vocabulary. Yet, it is still considered a useful technique in teaching and acquiring vocabulary, mainly because it provides the learners with fast answers while looking for the meaning of a word on the spot.

L2 learners have always employed translation to learn new vocabulary or explore their meaning in the target language (Alroe \& Reinders, 2015). Before the emergence of technologyenabled translation software, students and academics used to resort to traditional dictionaries, monolingual or bilingual, but nowadays, almost everyone seems to have turned to the following resources: search engines, Online Translators (OTs), Online Dictionaries (ODs) (O’Neil, 2019) for 
multiple purposes related to teaching or learning vocabulary. Research in foreign language teaching has revealed that one of the practical uses of technology is to simplify vocabulary acquisition (Shrum \& Glisan, 2010). Nevertheless, this task does not go unchallenged, given several impediments L2 learners encounter when using MT to check the meaning of vocabulary in context.

First, L2 learners assume that online dictionaries provide an ideal solution to problems associated with vocabulary acquisition tasks, and they are addicted to the uninformed uses of the online translation software. Second, instructors lack the required academic and pedagogical background to address the challenges related to online translators' arbitrary uses in vocabulary acquisition. Third, although using electronic translation tools is pervasive among L2 learners and users and is a frequently-discussed academic topic (Clifford et al., 2013), not much scholarly work has investigated the role of MT in learning vocabulary in the EFL classroom. In other words, there is a pressing need for exploring the role of MT in different EFL activities, including vocabulary acquisition (Sabtan, 2020), with a particular reference to Arabic-speaking L2 learners. This study is pertinent and significant because it aims to bridge the gaps in academic research on the value of technology for vocabulary acquisition among L2 learners. The study aims to test online translators' effectiveness in answering vocabulary questions among ESL Arabic-speaking learners in a private Omani university. It also highlights the challenges that L2 learners face when learning about the uses of vocabulary in context. The empirical study will attempt to answer the following questions:

1. Is using online translation software an optimal strategy to learn vocabulary among L2 Arabic-speaking learners?

2. Has machine translation managed to replace traditional dictionaries in the effective acquisition of vocabulary?

3. What challenges do L2 learners face when using online translators to answer vocabulary questions?

4. What appropriate pedagogic strategies can instructors adopt for better teaching of vocabulary vis-à-vis the use of technology?

The following literature review will highlight the relevance of technology to teaching and learning vocabulary, discussing its affordances and limitations in ESL/EFL teaching.

\section{Literature Review}

Machine Translation (MT), also referred to as 'Online Translator' software (OT), goes back to the middle of the twentieth century (Akbari, 2014; Poibeau, 2017). It is a branch of "computational linguistics that investigates the use of software to translate text or speech from one natural language to another" (Al-Tuwayrish, 2016, p. 5). Electronic translation may occur with the intervention of human beings or without it (Akbari, 2014). By and large, the majority of EFL students use "MT as a dictionary (specifically MT is easier than a dictionary)" (Clifford et al., 2013 , p. 112) to translate lexical items or check up their meaning in vocabulary learning activities (Chandra \& Yuyun, 2018; Clifford et al., 2013). Using MT as a translation tool applies to diverse language combinations, including English/Arabic. Several studies researched this function of MT 
from the perspective of Arabic-speaking learners of English (See Abu-Al-Sha'r \& AbuSeileek 2013; AlQahtani, 2015; Kumar, 2012; Medvedev, 2016). Kumar (2012) remarked that using MT among Arabic-speaking ESL learners, especially in Gulf countries, is prevalent in vocabulary activities as these learners use MT to translate the new vocabulary and understand their meaning in the target language.

It is undeniable that using MT in L2/FL learning contexts has become a fait accompli and is expected to grow even further with the increasing demand for online learning in the post-COVID era. Fundamentally, EFL learners use MT in vocabulary learning activities because it has many affordances. Shrum and Glisan (2010) said there is "enough research to confirm that the use of technology has a small but positive effect on L2 reading, writing and vocabulary development" ( $p$. 454). Other researchers highlighted MT's value in providing convenient and instant support to EFL learners in vocabulary learning activities (Al-Tuwayrish, 2016; Lee, 2019), especially in the classroom context where both instructors and learners are mindful of the constraints of time. Additionally, MT has other positive aspects for being free of charge and providing translation services in different languages. MT software has recently been updated to provide additional functions to giving the direct meaning of words. The following quote explains all these advantages:

It has a free access. The users only need to open its website in a browser or download the app in their gadget to use it. It is also instant, in a quick click, the users could get the translation result. It also provides a variety of languages. Photo recognition becomes one feature in GT application in students' smartphone that they use in order to save their time, especially when they try to understand some English texts. (Chandra \& Yuyun, 2018, p. 229)

Despite the positive aspects associated with the use of MT in terms of promptness and other learner-support features, "Such immediacy also has a negative side to it" (Medvedev, 2016, p. 184). MT has several limitations that cannot be overlooked from a pedagogical and academic perspective as they undermine the effectiveness of online translators (O'Neil, 2019). Certainly, MT is a handy tool to be used in the EFL classroom, but it has shortcomings in understanding the use of vocabulary in context as it may yield inaccurate results. The source of the challenge is not only in using MT to check the meaning of vocabulary. Instead, it is in the learners' overdependence on their native language to understand new vocabulary in the target language. Chapelle (2003) observed that "in English language teaching the common wisdom seemed to suggest that learners should develop their strategies for figuring out the meaning or guessing the right word rather than relying on the first language" (p. 48). AlQahtani (2015) noted that, regardless of the instructors' techniques in teaching vocabulary, they need to provide examples of vocabulary used in rich and multiple contexts, which MT may fail to offer.

Constantinescu (2007) discussed the integrated relationship between learning vocabulary and reading comprehension and the importance of using technology to enhance this relationship in the classroom, concluding that in reading activities, full comprehension requires a

Arab World English Journal for Translation \& Literary Studies 
contextualized understanding of the meanings of vocabulary. It is not surprising that teaching L2 students new vocabulary is closely related to reading comprehension exercises because vocabulary acquisition does not happen in isolation of a particular context. Students also need to learn how and when to use different lexical items. The fact that teaching/learning vocabulary needs to occur in context is deeply rooted in the nature of meaning and the issue of polysemy. Meaning is a variable component which "does not reside in language; it is produced in practice" (Canagarajah, 2007, as cited in Lomicka, 2020, p. 310). The concept of meaning has multifaceted levels, including, lexical meaning (dictionary meaning), propositional meaning (contextual), expressive meaning, presupposed meaning, and evoked meaning (Baker, 2018). These different layers of meaning make it difficult for MT to "distinguish multiple meanings of the source language words in the target language" (Akbari, 2014, p. 7). Latest developments in computational linguistics have introduced contextualized MT models such as Rule-based MT and Statistical MT that have provided partial solutions to such problems (Akbari, 2014). Still, the inability of MT to think critically makes the absolute reliance on such software disruptive. Akbari (2014) discussed different types of shortcomings in MT, including syntactic problems, idioms, slangs and expressions, lexical problems, and paralinguistic problems. The researcher concluded that it is still impossible for MT to function accurately without human beings' intervention.

Although most EFL students use MT as a dictionary (Clifford et al., 2013), and this is visibly the case among Arabic-speaking EFL learners, practically, there are some functional differences between MT and ODs. Like OTs, ODs provide a direct and easy means for vocabulary acquisition by English language learners (Nomass, 2013). The main difference between them is that most ODs provide contextualized examples of vocabulary uses, which is not the case in all OTs. According to Jin and Deifell (2013), "online dictionaries that offer more contexts of usage lead to more successful language use by second language learners" (p. 517), and they are used by learners at the level of words when they become "difficult to figure out from the context" (p. 522). An empirical study conducted by O'Neil (2019) to investigate L2 students' opinions about ODs and MT observed that both ODs and MT software had the same results in terms of the number of students who use them in their L2 tasks, including vocabulary checking. But there was a difference between the two in terms of students' attitudes. To clarify, ODs received a higher percentage of positive attitudes than OTs. The results showed that " $93.9 \%$ of comments about online dictionaries were judged to be positive" (O'Neil, 2019, p. 165) compared to $75.6 \%$ of positive opinions about online translators. The study explained that the source of the negative feedback on OTs' performance was related to their inaccuracy and unreliability, compared to ODs that did not receive similar feedback. This variation in students' attitudes vis-à-vis the reliability of OTs and ODs is related to the fact that ODs involve the students in reflective thinking. On the other hand, OTs seem to be used "as a sort of 'crutch' to help them complete assignments (...) at least in some cases, online translation is being used as a means to an end as opposed to a learning tool" (p. 172). Jin and Deifell (2013) explained that the value of online dictionaries is seen "in their innovativeness, which includes their convenience, quick updates, interactivity, and potential for designer/user collaboration" (p. 516).

Arab World English Journal for Translation \& Literary Studies 
As a matter of fact, unlike ODs, OTs have a relatively deterministic function that does not help L2 students to develop their skills of reflection as autonomous learners. Nonetheless, OTs can be helpful in learning vocabulary if students receive guidance on using them "effectively and critically" (Reinhardt, 2020, p. 239) as learning tools. Viewing OTs or other technological resources as a learning tool is indispensable for L2 learners to use them constructively. Seeing technology in terms of the tool metaphor is in harmony with the communicative approach that "shifted language teaching practices from a focus on translation, text, and memorization to techniques that provided authentic opportunities for learning through interaction and meaningful language use" (Reinhardt, 2020, p. 235). While ODs can be more reliable than OTs in learning new vocabulary and mastering their use in context, learners need to be mindful of how best to use them, as expressed in the following quote:

Translation programs (...) may lack cultural knowledge and the application of higher-level thinking that students would normally apply to creating their own expression. Students should be cautious in using a translation program because such programs do not help them learn how to interpret and communicate in the TL. Similarly, use of an online dictionary should be limited to consulting the meaning and proper use of a word, while also verifying that the correct meaning or connotation of the word is selected. (Shrum \& Glisan, 2010, p. 465)

Despite the challenges L2 learners meet when using MT or ODs to identify the proper uses of words, their application is inevitable among all L2 learners. Clifford et al. (2013) highlighted this idea by stating that "these applications and programs are here. They are pervasive. They are being actively promoted. They are being actively updated and tweaked. They are garnering widespread attention and, most importantly, they are being used by our students" (p. 116). Therefore, it is essential not to throw the baby with the bathwater but rather to see how instructors can integrate technology with L2 learning activities without influencing the quality of the learning process. Clifford et al. (2013) pointed out that as instructors, we should explore the use of MT in vocabulary acquisition with our students rather than prevent them from using it. In other words, instructors need to reconsider their pedagogic practices in teaching vocabulary in the L2 classroom, given the unavoidable use of MT by L2 learners. Therefore, it is necessary to think of strategies that can be adopted by both instructors and learners to maximize the benefit of OTs and ODs. For instance, learners need to receive training in how to "use online translators and online dictionaries in concert to facilitate language learning and develop effective digital literacy practices" (Jin \& Deifell, 2013, p. 525). This can help them "avoid semantic breaches" (Medvedev, 2016, p. 187). In other words, recent research calls for merging the use of technology, as a tool, with the role of instructors who are required to guide their students on the most effective uses of OTs (Medvedev, 2016; O' Neil, 2019; Shrum \& Glisan, 2010).

According to Nomass (2013), integrating the role of technology with that of the instructor is an optimal way to achieve "advanced learning results" (p. 111). Some EFL instructors are not speakers of the target language, so they cannot rely on MT to verify their students' correct 
understanding of the actual meaning of vocabulary in context (Chandra \& Yuyun, 2018), but still, there are several strategies that EFL instructors can adopt in order to complement the role of the translation software in the learners' acquisition of new vocabulary. If used in a pedagogicallysound manner, these strategies can develop students' skills to use MT effectively and independently in advanced phases without the guidance of their teachers. First and foremost, instructors need "to show students the benefits and drawbacks of instant translation as a learning tool so that they are not lost but, instead, found in meaningful language practice" (Medvedev, 2016, p. 192). For example, teachers can highlight the disadvantages of OTs or ODs "by illustrating selected errors in a brief lesson" (Sweley, 2008 as cited in Shrum \& Glisan, 2010, p. 465). Secondly, instructors need to teach their students the skill of critical thinking (Jin \& Deifell, 2013), which is important to employ in online translation when dealing with the issue of polysemy because "critical thinking really comes into play when students scan the available translated option in search of the proper equivalent" (Medvedev, 2016, p. 188). An example of one level of meaning that MT does not process successfully is expressive meaning. Learners can have access to this level of meaning via an intervention from their instructors who have the required experience to "expand their critical awareness of the emotional impact of words" (Medvedev, 2016, p. 189).

Following the rise in using OTs and ODs among L2/FL learners, research studies started investigating their relevant uses quantitively and qualitatively. Jin and Deifell (2013) accentuated the need for research on "Which mobile dictionaries are used in FL learning and how these dictionaries are used" (p. 526). In the majority of studies that discussed the uses of MT in the context of ESL/EFL, Google Translate (GT) was singled out as one of the most popular MT tools among learners and instructors alike. Medvedev (2016) stated that "Google Translate is likely to be most frequently referred to by the English language learners to look for the translation of individual words" (p. 186). Accordingly, GT is used as a dictionary to find words or translate them into the target language (Chandra \& Yuyun, 2018) when students are involved in a particular activity or assignment. Clifford et al. (2013) pointed out that the pervasive use of free MT online programmes like GT is revolutionizing the way students interact in the second language. This has triggered interest in researching the value of this tool in EFL learning activities.

Several studies discussed the uses of GT among Arabic-speaking EFL learners (Abu-AlSha'r \& AbuSeileek, 2013; Kumar, 2012; Medvedev, 2016). Abu-Al-Sha'r and AbuSeileek (2013) concluded that since 2008 "Google has achieved prominent advancement in the field of electronic translation" (p. 533), compared to other systems. Chandra and Yuyun (2018) indicated that "GT is helpful if it is dealing with only words" (p. 236). This is related to the fact that GT has high accuracy in translating vocabulary because it identifies the uses of a specific vocabulary based on many statistical patterns in millions of documents (Abu-Al-Sha'r \& AbuSeileek, 2013; Medvedev, 2016). Accordingly, GT was commended as "one of the easiest and most accessible tools to help users meet their translation needs. Since it offers quick and rather accurate dual translation services" (Medvedev, 2016, p. 183). Yet, there are still some reservations on using GT as an absolute resource in learning vocabulary. For example, it lacks accuracy when used for translating

Arab World English Journal for Translation \& Literary Studies 
vocabulary in context (Chandra \& Yuyun, 2018). besides, the quick and convenient access that GT gives encourages over-dependence among learners and makes specific cognitive processes such as memorizing and remembering words more challenging (Jin \& Deifell, 2013).

Kumar (2012) described the use of GT by Arabic-speaking EFL learners to learn vocabulary as a prevalent and useful but not always reliable tool in learning English well because sometimes "it changes the meaning of the sentence" (p. 444). Medvedev (2016) conducted a study on the use of GT as a tool for translating vocabulary among Arab learners of English in Oman. The study explained how GT may lead to "misunderstanding in the choice of words" (p. 185), particularly in the case of neologisms and synonyms "when the Arabic part appears to be completely the same, whereas the English equivalent presents a significant difference in meaning" (p. 186). The paper concluded that instructors need to adopt practical techniques to show their students how to employ GT and other translation tools in learning vocabulary away from bad practices. Al-Tuwayrish (2016) studied the use of MT among Arabic-speaking EFL learners and pointed out that the product of MT certainly needs to be examined by experienced people and that MT "is a potent tool to be used with caution. This is especially true in EFL situations as in Saudi Arabia where the student community is ill equipped to verify the reliability of machine translated texts" (p. 9). Jin and Deifell (2013) explained that instructors are required to develop professional experience about the reliability of different OTs or ODs to provide their students with relevant guidance, as explained in the following quote:

Online dictionaries and other digital resources, such as online translators, have great potential in assisting FL learning inside and outside the classroom. Although FL learners have awareness of the strengths and weaknesses of these tools, FL instructors should develop and facilitate a better understanding of the quality and functions of various online dictionaries in the target language. Instructors can provide the necessary guidance to help students better take advantage and avoid the pitfalls of tools that FL learners are already using. (p. 525)

The empirical studies conducted so far on the use of MT in vocabulary acquisition among Arabicspeaking L2 learners are valuable and pertinent. However, they are limited in number and hardly provide empirical evidence on the challenges that students face while identifying the appropriate uses of vocabulary in context. The following empirical study will attempt to bridge a gap in this context, focusing on the nature of problems students face in answering vocabulary questions and the factors that play a role in determining the 'correct' uses of vocabulary in context. The study also highlights the skills that instructors need to focus on in training their students in the appropriate uses of vocabulary.

\section{Methodology}

This empirical study was conducted based on a combination of quantitative and qualitative methodology to explore the effectiveness and limitations of using OTs in answering vocabulary questions and using vocabulary effectively and communicatively. The analysis dealt with the 
collected data descriptively by focusing on data that showed a noticeable deviation from the norm, which was detected by examining the results' standard deviation (SD).

\section{Participants}

The participants were selected based on the convenience sampling method. They were forty-seven ESL students in their fourth academic year at an Omani private university during the Summer Term 2019-20. Usually, students who are about to graduate can complete their remaining courses during the summer term to expedite their graduation. The study coincided with the onset of the online learning mode following the COVID-19 pandemic. All participants were native Arabic speakers and were taking an advanced course in English language and communication skills to prepare for their IELTS exam following their graduation. In an IELTS exam, vocabulary accounts for $25 \%$ of the total marks assigned for the writing and speaking tests (Wang, 2018), and advanced knowledge of the effective use of vocabulary is indispensable to perform well in the four sections of the exam. The criteria for assessing an applicant's ability to use vocabulary functionally comprise accuracy, appropriateness in terms of context, the uses of word combination, and the applicant's ability to express connotative meanings and attitudes precisely.

\section{Research Instruments}

The participants had to complete an authentic vocabulary quiz within fifteen minutes using OT software. The students accessed the test via the testing functions available on Moodle, and they completed it from the comfort of their home without any observation mechanism. They had to answer 5 MCQs that prompted them to choose the most appropriate and accurate vocabulary in terms of lexical sequence, context, and communicative function (expressive meaning) to fill in the gaps in statements that provide contextual cues about the appropriate uses of vocabulary. The table below gives full information about the questions and the multiple-choice answers. It is worth mentioning that the model answer appears in the table under choice A.

Table One: The quiz content by questions, multiple choices and model answer

\begin{tabular}{|l|l|l|l|l|l|}
\hline $\begin{array}{l}\mathrm{N} \\
\mathrm{0}\end{array}$ & $\begin{array}{l}\text { A (model } \\
\text { answer) }\end{array}$ & $\mathrm{B}$ & $\mathrm{C}$ & $\mathrm{D}$ \\
\hline $\begin{array}{l}\text { During the Khareef, Dhofar } \\
\text { becomes an attraction place } \\
\text { for tourists who come to } \\
\text { enjoy the rain-soaked } \\
\ldots . . . . . . \text { mountains, valleys } \\
\text { and coastlines. }\end{array}$ & spectacular & great & green & natural \\
\hline 2 & $\begin{array}{l}\text { In order to protect the } \\
\text { environment, it is necessary } \\
\text { to ........ the means of }\end{array}$ & renew & convert & adapt & recharge \\
\hline
\end{tabular}

Arab World English Journal for Translation \& Literary Studies 
AWEJ for Translation \& Literary Studies Volume, 5 Number 1. February 2021

\begin{tabular}{|c|c|c|c|c|c|}
\hline & $\begin{array}{l}\text { transportation into } \\
\text { environment-friendly } \\
\text { vehicles. }\end{array}$ & & & & \\
\hline 3 & $\begin{array}{l}\text { The computer came as an/a } \\
\ldots . . . . . \ldots . \text { invention that } \\
\text { changed all aspects of life } \\
\text { all over the world. }\end{array}$ & modern & up-to-date & sophisticated & revolutionary \\
\hline 4 & $\begin{array}{l}\text { There was a traffic jam as a } \\
\text { result of the accident, and } \\
\ldots . . . . . . . . \text { were advised to } \\
\text { avoid the area in order not } \\
\text { to be late for work. }\end{array}$ & commuters & passenger & pedestrians & cyclists \\
\hline 5 & $\begin{array}{l}\text { On the weekend, we go to } \\
\text { visit my grandmother who } \\
\text { has a large house with a } \\
\text { garden ........... of town. }\end{array}$ & in the suburbs & in the middle & onthe outskirts & In the centre \\
\hline
\end{tabular}

The limitations of the data collection method are threefold. The first limitation is the small number of vocabulary examined in the experimental study. This was addressed by testing the uses of the selected vocabulary among a relatively good number of students and providing a quantified description of the data behaviour, as the analysis will reveal. The second limitation in the research methods is related to the fact that the students' answers were collected from an authentic quiz, which put them under the pressure of time and their motivation to get high grades. Normally, students have high expectations about their results when it comes to answering vocabulary questions, considering OTs' availability. Little do they know that their failure in answering some vocabulary questions or even reading comprehension questions can be highly attributed to their failure in understanding the meanings and uses of words in context and following specific sequential patterns or communicative functions.

The main shortcoming here is that the activity was not designed as a regular vocabulary acquisition exercise in the classroom, but it is worth mentioning that the students were involved in similar classroom activities which were designed for the purpose of learning the uses of vocabulary in context and in different communicative situations. Another important point is that some questions were designed in the context of the students' cultural background to test their ability to select and use vocabulary within a situational context and in a way that develops their critical thinking and cross-cultural communication. The third limitation in the methodology is that the students answered the questions without any monitoring mechanism since they completed the test online, which means that they had access to each other's social media like WhatsApp groups,

Arab World English Journal for Translation \& Literary Studies 
Facebook, and others. This may undermine the value of the results as students would be tempted to copy the responses from each other. The section on the discussion will provide details on how this limitation was addressed by the researcher.

The data were collected using the tools available on Moodle, including the quiz results as grades, excel sheets of students' responses, as well as statistics generated by the Learning Management System (Moodle), and then the results were analysed by observing several criteria. The main criterion is the level of variation in the results of the students who answered the five vocabulary questions. The researcher studied the collected data to detect whether the results of the quiz showed sporadic distribution (high SD) or whether they were concentrated close to the mean (average), showing a noticeably-low SD in all the questions. If the data show a very low SD in all the results, this can be interpreted in one of the following ways:

1. The students copied the responses from each other without trying to think critically, which casts doubt on the validity of the experimental research.

2. The students have the same level and academic background, which is highly improbable since university students who take ESL language courses in Oman come from different disciplines and have different levels.

3. The vocabulary questions pose no issues or challenges for the students to answer correctly, which casts doubt on the validity of the examination content as exams are not only assessment tools. They are also pedagogical tools.

4. If most questions are answered incorrectly, then the exam content is challenging and not appropriate to the students' level.

5. If all questions are answered correctly, then using MT is effective. This interpretation promotes the use of OTs as optimal solutions for vocabulary acquisition among ESL learners.

On the other hand, if all the results show a high SD, this means that the tested students come from different academic backgrounds or levels, explaining why the data is overstretched. In both cases, i.e., whether the $\mathrm{SD}$ is minimal or maximal, the data behaviour is indicative of a learning issue that is worth studying and investigating to uncover the possible reasons behind the abnormal behaviour of the data. Analysing the results by observing where exactly in the data there was a very low/high SD provides empirical evidence about the validity of the quiz and the responses provided, on the one hand, and highlights any learning or pedagogic issues that need to be addressed vis-à-vis the research's main topic, on the other hand. This method of data analysis is of particular significance as it unveils the types of difficulties that learners face in their attempt to acquire vocabulary and raises their awareness about the challenges associated with the use of OTs in the acquisition of vocabulary. The data analysis also gives instructors insight into the obstacles students face while using OTs in vocabulary acquisition. Accordingly, they become mindful of the aspects they need to focus on in guiding their students and addressing their relevant educational and self-learning needs.

Arab World English Journal for Translation \& Literary Studies 


\section{Findings}

This section provides a general idea about the empirical study's findings, vis-a-vis the methodology and the research questions. The results show that there is variation in the SD of the answers provided by students in all five vocabulary questions. The SD of the responses hit different values, which has implications for the methodology used in collecting the data. To clarify, the fact that the students completed the quiz unobserved did not interfere with their choices of the answers and did not influence the authenticity of the responses. Otherwise, the SD in all the results would be close to $0 \%$, which is not the case, as clarified in Table Two below.

The total grade for the exam was five marks, and the total average (mean) of students' grades reached approximately 2.57 (51.4\% of the total grade). This value is indicative of an essential analysis criterion, namely the normal variation in the academic level of students. For example, an average value that is close to the minimum value of zero or the maximum value of 5 would be indicative of abnormal variation in the results due to cases of students copying from each other or homogeneity in the level of students. In other words, the initial examination of the results against the assumptions provided in the earlier account on methodology leads to the following findings on the reliability of the vocabulary quiz content and the testing criteria:

1. There were no noticeable cases of students copying from each other.

2. There was variation in the academic background and language level of the students.

3. There was variation in the content of the quiz and gradation in difficulty vis-à-vis different testing criteria.

4. The variation in the results is reflective of the appropriateness of the quiz to the students' level.

The following table provides the details on variation in the results of each question by the SD.

Table Two: variation in the SD of student' responses

\begin{tabular}{|l|c|c|}
\hline Question title & $\begin{array}{l}\text { Students' } \\
\text { Answers }\end{array}$ & SD \\
\hline Vocabulary Q1 & 47 & $0.00 \%$ \\
\hline Vocabulary Q2 & 47 & $33.73 \%$ \\
\hline Vocabulary Q3 & 47 & $49.14 \%$ \\
\hline Vocabulary Q4 & 47 & $28.21 \%$ \\
\hline Vocabulary Q5 & 47 & $20.40 \%$ \\
\hline
\end{tabular}

Arab World English Journal for Translation \& Literary Studies 
The data are further represented as a bar graph (graph one below) to give a clearer idea about the variation the results.

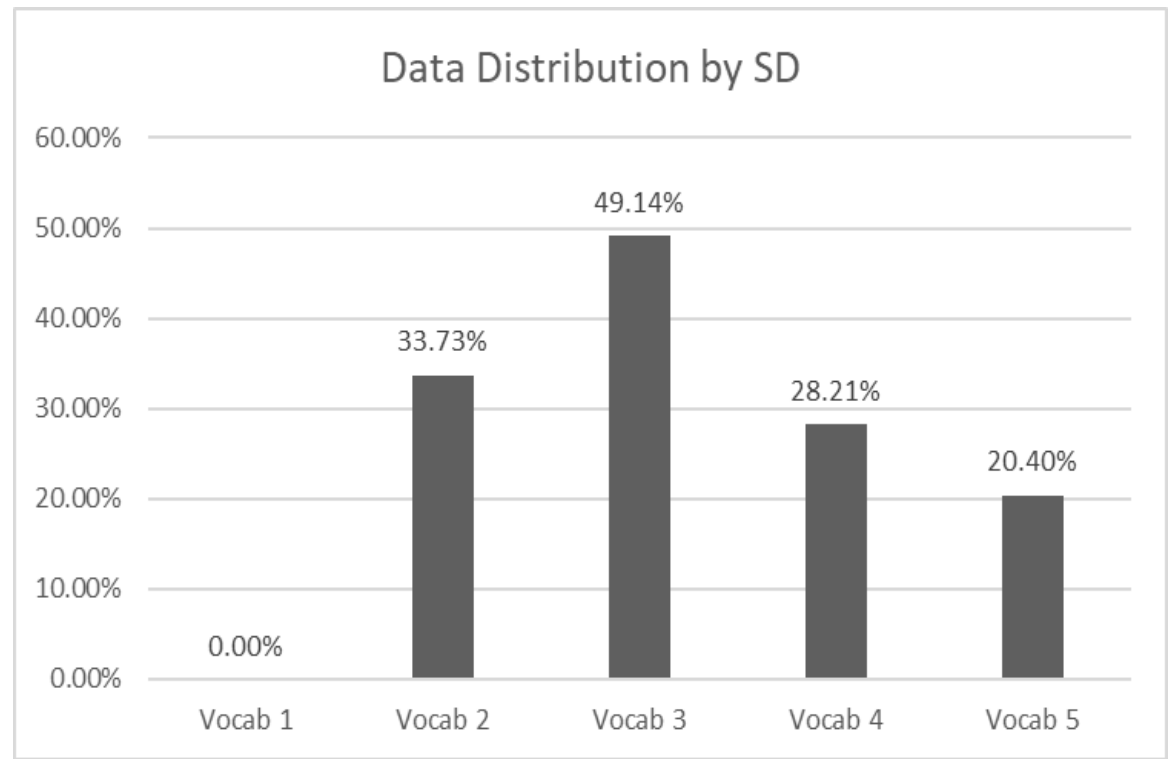

Figure One: Data Distribution by SD

As for the results of the empirical study in relation to the research questions, the initial examination of the data shows that the total average of students' grades did not hit $100 \%$ and was nowhere near this value, which casts doubt on the effectiveness of using MT in all cases of vocabulary acquisition. Besides, the participants' individual results showed that none of them answered all the vocabulary questions correctly. In general, the collected results highlight the following findings:

1. Online translation software is merely a tool and not a reliable strategy that L2 learners can adopt to use vocabulary appropriately.

2. MT has not succeeded in replacing traditional bilingual dictionaries in using vocabulary effectively.

3. Students who answer vocabulary questions by relying solely on MT face challenges that disrupt their full comprehension and eventually leave a detrimental impact on their learning.

The following section on the discussion will investigate the nature of the challenges students faced when using MT to identify the appropriate uses of words and further analyse the results in relation to the literature review.

\section{Discussion}

This section provides a quantitative and descriptive reading of the results in relation to the different assumptions discussed in the literature review about using technology for the acquisition of vocabulary among L2 learners. The fact that none of the students got a full mark (5/5) although 
they had access to OTs further confirms the need to study the role of OTs in the acquisition of vocabulary and identify the sources of challenge. The implication here is twofold: first, students use online translators to translate individual vocabulary out of context, which is precisely what L2 learners used to do when checking traditional bilingual or monolingual dictionaries before the technology revolution and the advent of MT. This practice in learning new vocabulary and using them in different contexts reflects the shallow understanding that ESL learners have of the five levels of meaning referred to in the literature review. For example, students are not cognizant of the issues that may emerge as a result of the synonymy and polysemy of lexical meaning. Second, the students were under the influence of their mother-tongue linguistic habits, which forced them to select the vocabulary that were natural for them. For example, in question two, 37 students out of 47 gave the wrong response because they were under the influence of Arabic. It is more common in Arabic to talk about 'converting' the means of transportation into environment-friendly vehicles than 'adapting' the means of transportation into environment-friendly vehicles. Also, in question four, 32 students out of 47 gave the wrong answer because the concept of 'commuters' is not lexicalized in Arabic, which put them under the influence of the more common vocabulary 'passengers,' although this word is not appropriate to use in the context of 'traveling to work'.

Examining the SD of the results highlights another aspect of vocabulary acquisition. As the table of the data and the graph representation above show, the most prominent result is in the first question with data that show a SD close to zero. This means that the results centred on one answer which is the wrong answer from a communicative perspective. The question was reflective of the learners' cultural background as they live in a tourist attraction area known for its spectacular landscape. The word 'spectacular' has a positive expressive meaning compared to the two other vocabulary that the learners selected to answer the question. The majority of students chose words with a neutral meaning 'natural' and 'green.' The only interpretation for this is the learners' tendency to choose the vocabulary that looks familiar for them and reflects visible features of their environment, as opposed to communicatively-embedded features.

The context was rich in cues that guided the learners to using a vocabulary with prominent positive connotations such as: attraction place, tourists, enjoy, rain-soaked. The students did not seem to observe these cues, which shows that their use of OTs was quite impulsive and uninformed, and that they were under the influence of their native language while using the tools available for vocabulary acquisition. This finding also shows the student's inability to practice critical thinking or communicate culturally-embedded content accurately. This is another point of concern that was discussed in the literature review on the shortcomings of using MT in vocabulary acquisition. Interestingly, all the answers provided are correct, vis-a-vis the lexical and propositional levels of meaning. The issue here is whether all four answers provide a communicatively accurate use of the vocabulary, something which OTs would fail to address. It is worth noting that following the quiz, all the students argued that they deserved a full mark for their apparently-correct- yet simplistic- response to question one. The instructor explained the forceful communicative function of an expression like 'spectacular landscape/mountains' in 
promoting the area to a tourist, compared to using an expression like 'green or natural landscape'. The students were convinced, and the argument reached a peaceful settlement.

\section{Conclusion}

Using MT in vocabulary acquisition among EFL learners is an indisputable trend that is impossible to reverse, but it has its shortcomings and challenges. This research investigated the challenges ESL Arabic-speaking learners encounter when relying on MT in vocabulary acquisition. The empirical study was limited in the number of vocabulary examined. Still, the number of participants was quite representative, considering the quantified analysis of the results by using statistical tools like the average and the SD of data. The study's findings confirmed the results of earlier research that MT has not fully bridged the existing gap in using vocabulary among L2 learners and cannot function as a reliable strategy to learn about the uses of vocabulary in context. The study is valuable because it provides empirical evidence about the nature of problems students face in their absolute reliance on MT and gives valuable insight into the sensitivity of teaching ESL learners about the effective uses of vocabulary and the role of OTs in vocabulary acquisition among ESL learners.

\section{Implications}

The empirical study provides several significant implications for further consideration by ESL scholars, educators, as well as learners:

First, online dictionaries are mere tools that can help learners to perform specific cognitive tasks, just like traditional monolingual or bilingual dictionaries. To maximize their benefits, they need to be used jointly with critical thinking and contextualization strategies. Students may think that MT is a magical solution for contextualizing all words' meanings whenever needed. Instructors should develop their pedagogical methods to teach their students how to identify the meaning of words in context and use them in a sound, communicative manner. They are also required to practice using different types of OTs and ODs with their students in the classroom to provide them with practical examples about cases of error in MT and how to avoid/correct them. This way, both instructors and learners may form empirical perceptions about the most reliable OTs or ODs, bilingual or otherwise, in vocabulary acquisition.

Second, there is a need for future studies on vocabulary acquisition in other ESL learning activities such as reading comprehension, speaking exercises, and writing. Students always have high expectations about their results when it comes to answering vocabulary questions, considering OTs' availability. Little do they know that their failure to answer some reading comprehension questions is related to their inability to understand the meanings and uses of words in context and follow specific sequential patterns or communicative situations. This observation underlines the importance of raising awareness among ESL learners about the different levels of meaning and the value of distinguishing between these levels of meaning while acquiring new vocabulary and examining their uses in context (lexical or situational). Usually, studying the levels of meaning is part of the curricula of translation students considering the difficulties they encounter in choosing

Arab World English Journal for Translation \& Literary Studies 
target language 'equivalents' while translating. Understanding the complexity of meaning is indispensable for ESL learners who are under the influence of their mother tongue when learning new vocabulary or using them. This aspect of L2 teaching and learning is worth a careful study and pedagogic integration with the $\mathrm{L} 2$ educational process.

Third, it is crucial to raise the learners' awareness of the communicative aspects of vocabulary uses. This is something that MT is still incapable of responding to. Until MT specialists provide possible answers or strategies to deal with this source of challenge, instructors are required to address this issue in their classroom. A very sensitive aspect of teaching L2 learners about the communicative uses of vocabulary is relevant to their awareness about culturally-embedded lexical units and how to use them to be able to communicate cross-culturally.

Fourth, online learning management systems can provide a useful tool for researching pedagogical and learning aspects. This implication is timely, considering the recent shift to online or blended learning in higher education institutions worldwide. Learning management systems are a rich source of data that equip academic researchers with the necessary empirical research tools. Examples of LMS' sources of data include exams' results and the relevant statistics on students' responses.

\section{About the Author:}

Dr. Lamis Ismail Omar is Assistant Professor of Translation and ESL at Dhofar University, Oman. She holds a doctorate in Translation Studies from Durham University, the UK. She taught translation, conference interpreting, ESL and literary criticism at Damascus University, and she also has long professional experience in English/Arabic translation and conference interpreting. Her research interests include translation and conference interpreting, the conceptual theory of metaphor, Shakespeare's metaphors as well as teaching English as a Second/Foreign Language. https://orcid.org/0000-0003-0246-5613

\section{References}

Abu-Al-Sha'r, A. M. \& Abuseileek, A. F. (2013). Advancement in productivity of Arabic into English machine translation systems from 2008 to 2013. Educational Research and Reviews, 8(9), 525538.

Akbari, A. (2014). An overall perspective of machine translation with shortcomings. International Journal of Education and Literacy Studies, 2(1), 1-10. DOI: 10.7575/aiac.ijels.v.2n.1p.1

Alagozlu, N. \& Kiymazarslan, V. (Eds.) (2020). Current perspectives on vocabulary learning and teaching. Newcastle upon Tyne: Cambridge Scholars Publishing.

AlQahtani, M. (2015). The importance of vocabulary in language learning and how to be taught. International Journal of Teaching and Education, 3(3), 21-34. DOI: 10.20472/TE.2015.3.3.002

Alroe, M. J. \& Reinders, H. (2015). The role of translation in vocabulary acquisition: A replication study. Eurasian Journal of Applied Linguistics, 1(1), 39-58. DOI: 10.32601/ejal.460588

Al-Tuwayrish, R. K. (2016). An evaluation of machine translation in the EFL Scenario in Saudi Arabia. Advances in Language and Literary Studies, 7(1), 5-10. Doi:10.7575/aiac.a 
Baker, M. (2018). In other words: A coursebook on translation (3rd ed). London: Routledge Taylor \& Francis Group.

Blake, R. J. (2008). Brave new digital classroom: Technology and foreign language learning, Washington: Georgetown University Press.

Boers, F. \& Lindstromberg, S. (Eds.). (2008). Cognitive linguistic approaches to teaching vocabulary and phraseology. New York: Mouton de Gruyter.

Chandra, S. O. \& Yuyun, I. (2018). The use of google translate in EFL essay writing. LLT Journal, 21(2), 228-238. DOI: 10.24071/llt.2018.210212

Chapelle, C. A. (2003). English language learning and technology: Lectures of applied linguistics in the age of information and communication technology, Amsterdam: John Benjamins Publishing Company.

Clifford, J., Merschel, L., \& Joan, M. (2013). Surveying the landscape: What is the role of machine translation in language learning? Revista D'Innovació Educativa, 10, 108-121. DOI: 10.7203/attic. 10.2228

Constantinescu, A. I. (2007). Using technology to assist in vocabulary acquisition and reading comprehension. The Internet TEST Journal, 13(2). Retrieved from: http://iteslj.org/Articles/Constantinescu-Vocabulary.html

Jin, L. \& Deifell, E. (2013). Foreign language learners' use and perception of online dictionaries: A survey study. Journal of Online Learning and Teaching, 9(4), 515-533.

Kumar, A. (2012). Machine translation in Arabic-speaking ELT classrooms: applications and implications. International Journal of Social Sciences and Humanity, 2(6), 442-445. DOI: 10.7763/IJSSH.2012.V2.142

Lee, S.-M. (2020). The impact of using machine translation on EFL students' writing, Computer Assisted Language Learning, 33(3), 157-175, DOI: 10.1080/09588221.2018.1553186

Lomicka, L. (2020). Creating and sustaining virtual language communities. Foreign Language Annals, 53(4), 306-313. DOI: 10.1111/flan.12456

Medvedev, G. (2016). Google translate in teaching English. The Journal of Teaching English For Specific and Academic Purposes: Special Issue, 4(1), 181-193.

Nomass, B. B. (2013). The impact of using technology in teaching English as a second language. English Language and Literature Studies, 3(1), 111-116. DOI: 10.5539/ells.v3n1p111

O’Neill, E. M. (2019). Online translator, dictionary, and search engine use among L2 students. CALL-EJ, 20(1), 154-177. Retrieved from: Https://Www.Academia.Edu/38360214/Online Translator Dictionary And Search Engine Use _Among_L2_Students

Poibeau, T. (2017). Machine Translation. Cambridge: Massachusetts Institute of Technology.

Reinhardt, J. (2020). Metaphors for social media-enhanced foreign language teaching and learning. Foreign Language Annals, 53(2), 234-242. DOI: 10.1111/flan.12462

Sabtan, Y. M. N. (2020). Teaching Arabic machine translation to EFL student translators: A case study of Omani translation undergraduates. International Journal of English Linguistics. 10(2). 184-197. DOI: 10.5539/ijel.v10n2p184

Shrum, J. \& Glisan, E. (2010). Teacher's handbook: Contextualized language instruction $\left(4^{\text {th }}\right.$ ed.). Boston: Heinle Cengage Learning.

Wang, I. K.-H. (2018). Learning vocabulary strategically in a study abroad context. Cham, Switzerland: Palgrave Macmillan.

Arab World English Journal for Translation \& Literary Studies

ISSN: 2550-1542 | www.awej-tls.org 